\title{
Study on the organic carbon and total nitrogen reserves in brown soils in the Chirchik river basin: A case study of Tashkent region, Uzbekistan
}

\author{
Abdunabi Bairov ${ }^{1 *}$, Khurshida Nuriddinova $^{1}$, and Shukhrat Juraev ${ }^{1}$ \\ ${ }^{1}$ Research Institute of Soil Science and Agrochemistry, 100179 Tashkent, Uzbekistan
}

\begin{abstract}
To identify the role in carbon stabilization, the content and reserves of SOC and TN in brown soils of the middle mountains of the Chirchik river basin of the Tashkent region of Uzbekistan were investigated in connection with the climatic conditions of the slopes of various topographic aspects. The content and reserves of SOC and N were the highest in the soils of the northern slope, and the lowest in the soils of the southern slopes; the eastern slopes, in this respect, occupied an intermediate position. The climates of slope exposures were the main factors influencing on the content and reserves of SOC and N in the profile of brown soils, indicating the need for separate consideration of carbon emissions from soils which are developed on slopes of various topographic aspects.
\end{abstract}

\section{Introduction}

The content and stocks of organic carbon (SOC) and total nitrogen (TN) in the profile of brown soils and topographic aspects affecting these indicators will help to identify the potential for carbon sequestration in soils of mediumaltitude mountains in the Chirchik river basin of Tashkent region.

The beneficial effect of organic matter on the physicochemical properties of soils, on the biological activity due to the cycle of $\mathrm{C}$ and $\mathrm{N}$, as well as on the maintenance of soil productivity are well known [1]. Soil also plays an important role in capturing atmospheric $\mathrm{CO} 2$ and in the emission of micro-gases $(\mathrm{CO} 2, \mathrm{CH} 4$ and $\mathrm{N} 2 \mathrm{O})$, which are radiationactive and enhance the greenhouse effect [2].

The large uncertainty in global carbon $(\mathrm{C})$ balances stems from soil carbon estimates and associated problems in soil organic carbon (SOC) distribution from local to landscape due to the lack of soil thickness information [3].

The study of carbon and nitrogen reserves in various types of ecosystems of Larix gmelinii larch forests in the Daxing'an Mountains in the Northeast China showed that more than $79 \%$ of soil carbon and $51 \%$ of soil nitrogen at a depth of $0-100 \mathrm{~cm}$ accumulated in the upper $50 \mathrm{~cm}$ soil layer [4].

SOC reserves in mountainous regions are highly heterogeneous due to topography, which can introduce significant uncertainty in the evaluation of SOC reserves in the region. At the same time, the zone of elevation and the position of the slope noticeably form the spatial structures of SOC reserves [5].

Alpine ecosystems of the Alps are very sensitive to changing environmental conditions, such as global warming. The results obtained suggest that a warmer climate and, consequently, more favorable conditions for biological activity, especially in cooler areas in the short and medium term will lead to an increase in the loss of accumulated weakly decomposed organic matter [6].

In the upper watershed of the Miyun Reservoir, northern China, environmental variables were more important for SOC and TN variability than land use and they should be taken into account while correctly assessing the regional impact of future land use changes on SOC and TN [7].

In the Antalya region of Turkey, the SOC is in Gray-Brown 4.36, Brown 4.36, Non-Calcareous Brown 6.54, Colluvial 7.55, Alluvial 7.80, Alluvial Coast 8.00, Hydromorphic 12.00 and Chestnut soil $14.90 \mathrm{~kg} \mathrm{C} \mathrm{m}{ }^{2}$, respectively [8]. In Turkey, the total SOC reserve in soils is $9.23 \mathrm{Pg}$ to a depth of $0.7 \mathrm{~m}$, and the annual emissions from the agricultural sector are 25.7 Tg C [9]. Therefore, in practice, areas with low carbon content should be preferred to areas with high carbon stores for use as carbon storage [10].

Topographic aspects induced by microclimatic differences and the type of plant communities were found to be important factors in the significant changes in SOC and TN stocks in the soils of the Bale Mountains of Ethiopia. About $45 \%$ of the SOC stocks in the $0-1.0 \mathrm{~m}$ layer of mineral soils were in the upper $0.3 \mathrm{~m}$, indicating a potentially large amount of $\mathrm{CO}_{2}$ that could be released from the top surface when vegetation is cut down and converted to grassland and cultivated land [11].

In the upper Blue Nile, SOC and TN stocks varied significantly depending on land use, topographic position and agroecosystem in four main land use types and three topographic positions at three sites: Dibati (lowland), Aba

\footnotetext{
*Corresponding author: abdunabi.bairov@gmail.com
} 
Gerima (central part of the country) and Guder (highlands) in the $0-50 \mathrm{~cm}$ soil layer. SOC and TN stocks were significantly higher in bush $(166.22 \mathrm{mg} / \mathrm{ha})$ and grassland $(13.11 \mathrm{mg} / \mathrm{ha})$ in Goodera. The lowest SOC and TN stocks were observed in arable land (25.97 and $2.14 \mathrm{mg} / \mathrm{ha}$ ) at Aba Gerima, mainly due to frequent and uncontrolled plowing and extensive biomass removal [12].

The largest reduction in TOC and TN stocks from agricultural land use can lead to soil degradation and contribute to increased atmospheric $\mathrm{CO} 2$ emissions in the seasonally dry tropical rainforest in the semi-arid region of Brazil [13]. Observations of the distributions of labile OC fractions along the hillside showed that soil erosion has less effect on dissolved DOC and the dynamics of light fraction of organic compound (LFOC), but has a noticeable effect on the distribution of solid POC. The distribution of total organic carbon from soil erosion mainly depends on the redistribution of POC [14].

Soil organic matter can be physically stabilized or protected from degradation through microaggregation, or binding by silt and clay particles, and can be biochemically stabilized through the formation of recharge of SOM compounds. Physicochemical characteristics inherent in soils determine the maximum protective capacity of SOM basins, which limit the increase in sequestration with increasing inputs of organic residues [15].

\section{Methods}

The study area is located in the Chirchik river basin and extends from $800 \mathrm{~m}$ above sea level up to about $2000 \mathrm{~m}$. In the belt of brown soils, the average annual air temperature varies from $12^{\circ}$ at the bottom to $5.4^{\circ}$ at the top, and the average annual precipitation ranges from 470 to $1000-1200 \mathrm{~mm} /$ year [16].

Brown soils in the Chirchik river basin have been studied by many researchers $[16 ; 17 ; 18 ; 19 ; 20 ; 21]$. The studied soils are widespread in the juniper woodland belt. The parent rocks are the products of limestone weathering [21].

Soil sections were laid on the northern, eastern and southern slopes. Selected soil samples were air dried and sieved through a $0.25 \mathrm{~mm}$ and $1 \mathrm{~mm}$ siever. The total SOC content was estimated by oxidation with K-dichromate in sulfuric acid, TN was determined according to Kjldahl. The texture was determined according to Kachinsky. The bulk density was determined by the core method using steel cylinders with a volume of $500 \mathrm{~cm}^{3}$ (height: $8 \mathrm{~cm}$; diameter: $8.7 \mathrm{~cm}$ ). The samples were dried at $105{ }^{\circ} \mathrm{C}$ to constant weight. The bulk density was calculated from the ratio of the dried mass and the volume of the soil core. $\mathrm{pH}_{\text {water }}$ of solil was determined using $\mathrm{pH}$-meter $\mathrm{PH} 3000$.

\section{Results and Discussions}

In the Western spurs of the Chatkal Range within the Tashkent region, brown soils are distributed in the vertical belt of medium-altitude mountains along the slopes of various exposures and steepness, characterized by significant differences in vegetation cover and hydrothermal regime. Brown soils develop with deep groundwater. They differ from sierozem soils located lower on above sea level in that they have a high content of organic matter and that the humus layer is stretched down the soil profile.

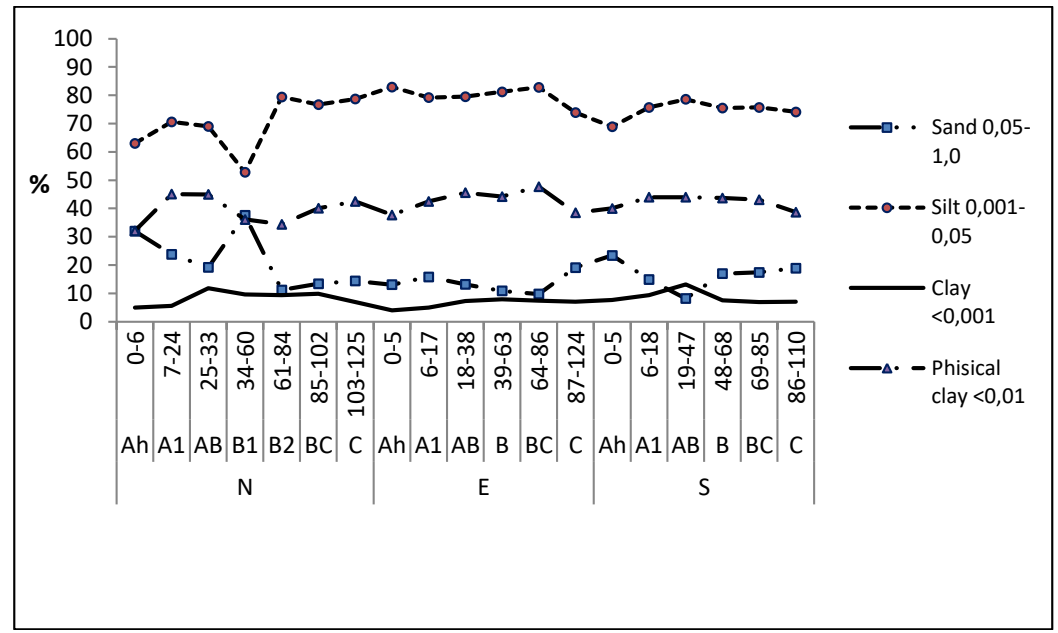

Fig.1. Texture of soils on different slopes

Natural brown soils are often used as hayfields and pastures for livestock, which significantly affects their condition. Therefore, the variety of data on their condition has a certain value in the development of measures for their protection. 
The basic properties of brown soils depend on their texture. The physical, physicomechanical and water properties, the ability of the soil to retain moisture and give it to plants, depend on the size and content of mineral particles and organic matter of the soil.

The studied soils are characterized by a high Silt content. Its content ranges from $69-82.9 \%$ of the total fractions. The Sand content is significantly lower $(8.2-32 \%)$ than Silt. The smallest indicators $(5-13.2 \%)$ refer to the Clay fraction. The content of physical clay ranges from $32.1-47.7 \%$ (Fig. 1).

The studied brown soils are calcareous soils. The content of $\mathrm{CO}_{2}$ carbonates is unevenly distributed over the soil profile. Shallow leaching of carbonates is observed in the soil profile. In the soil of the northern slope, the accumulation of the greatest amount of carbonates is observed in the AB horizon $(10.53 \%)$. In the soil of the eastern slope, carbonates are leached to the $\mathrm{AB}$ horizon and their content is $10.61 \%$. In the soil of the southern exposure, carbonates are also leached to horizon $\mathrm{AB}$ and their content is $10.92 \%$, which is more than in similar horizons of soils on the northern and eastern slopes. In all the studied soils in the underlying horizons, a decrease in their number relative to the $\mathrm{AB}$ horizon is observed, but the indicators remain rather high (Fig. 2).

The reaction of brown calcareous soils is alkaline. The $\mathrm{pH}$ of the soil on the northern slope along the profile ranges from 7.24 to 7.86. The highest $\mathrm{pH}$ values are confined to the $\mathrm{AB}$ horizon (7.86), where the highest content of $\mathrm{CO}_{2}$ carbonates is observed, and the lowest $\mathrm{pH}$ values are to the $\mathrm{Ah}$ and $\mathrm{A} 1$ horizons, 7.24 and 7.28, respectively. The soil $\mathrm{pH}$ of the eastern slope was also influenced by the content of $\mathrm{CO}_{2}$ carbonates. In the profile of this soil, the $\mathrm{pH}$ value ranges from 7.32 to 9 , and the highest $\mathrm{pH}$ values (7.98) refer to the horizon of accumulation of $\mathrm{CO}_{2}$ carbonates $(\mathrm{AB})$. In the soil on the southern slope, the $\mathrm{pH}$ values range from 7.41-7.99, and the highest $\mathrm{pH}$ values (7.99) also refer to the $\mathrm{AB}$ horizon, where accumulations of $\mathrm{CO}_{2}$ carbonates are observed (Fig. 2).

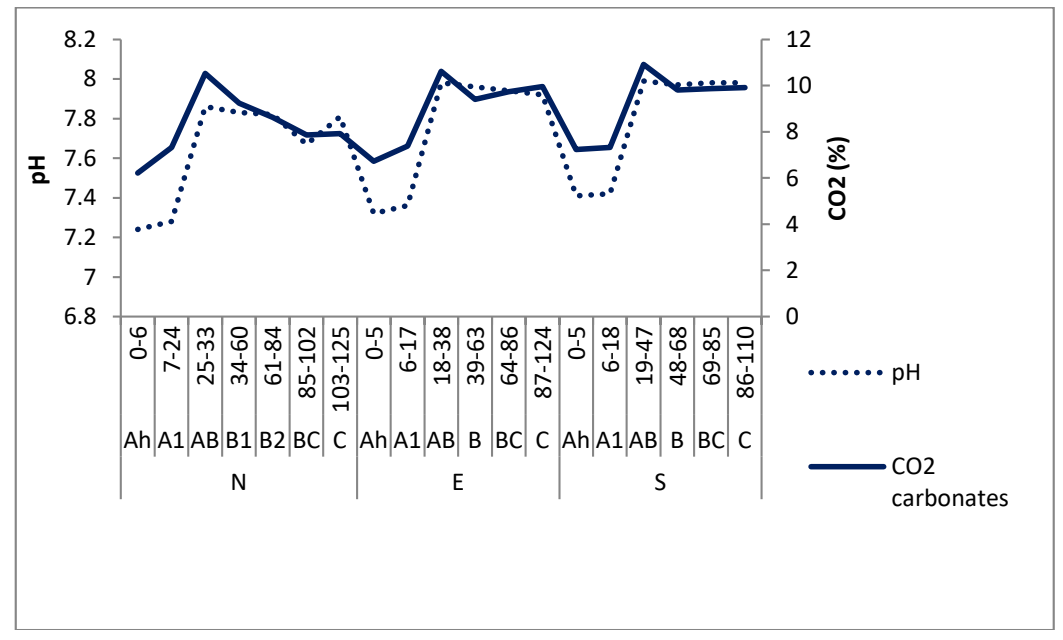

Fig.2. $\mathrm{CO}_{2}$ content of carbonates and $\mathrm{pH}$ of soils on various slopes

The bulk density of the soil depends on the mineralogical composition and texture of the soil, on the content of organic matter, the structure and porosity of the soil and it is important in the development of plants. The bulk density of the studied soils, depending on the exposure of the slopes, did not show any special differences. However, the bulk density of the upper horizons ( $\mathrm{Ah}$ ) sharply differed from those of the underlying horizons. The bulk density of the upper $(\mathrm{Ah})$ soil horizon of the northern slope was $1.12 \mathrm{~g} / \mathrm{cm}^{3}$, while in the lower horizons this indicator varied within $1.28-1.33 \mathrm{~g} / \mathrm{cm}^{3}$. In the soils of the eastern and southern slopes, the distribution of the bulk density was the same as in the northern one (Table 1).

Studies idicated that slope exposure has a strong influence on the SOC and TN content and reserves of brown soils. The northern shady slopes are characterized by a more favorable moisture regime and a relatively dense vegetation cover. The southern slopes are less humid due to strong evaporation of moisture and have a sparse vegetation cover. The eastern slopes in this respect occupy an intermediate position. These climatic differences in slopes had a significant impact on the content and stocks of SOC and TN in the soil profile.

In the $\mathrm{Ah}$ and $\mathrm{A} 1$ horizons of the northern slope soil, the SOC content was 4.52 and $1.72 \%$, respectively, and the content of TN was 0.46 and $0.21 \%$. The content of SOC and TN in the soils of the eastern and southern slopes significantly decreased in comparison with the soil of the northern slope. In horizons Ah and A1 of the soil of the eastern slope, the SOC content was 3.2 and $2.2 \%$, respectively, and the content of TN was 0.33 and $0.25 \%$. In the Ah and A1 horizons of the southern slope, the SOC content was 2.47 and $1.24 \%$, respectively, and the TN content was 0.25 and $0.17 \%$, which is significantly lower than in the soils of the northern and southern slopes. 
The highest SOC and TN stocks were observed in the soil of the northern slope. In a meter layer of this soil, the SOC and TN reserves were, respectively, 133, 36 and $16.18 \mathrm{t} / \mathrm{ha}$, while in the same soil layer on the southern slope, the SOC and TN reserves were significantly lower than in the soil on the northern slope and amounted to 99, 46 and 12.80 $\mathrm{t} /$ ha, respectively. In terms of SOC and TN reserves, the soil of the eastern slope occupied an intermediate position, and in the meter layer of soil, the SOC and TN reserves were 116.83 and $14.41 \mathrm{t} /$ ha, respectively.

In all studied soils, the content of SOC and TN decreased with the depth of the soil profile. In the soil of the northern slope, the SOC content from $4.52 \%$ in the upper Ah horizon dropped to $0.3 \%$ in the $\mathrm{C}$ horizon, while the TN content was 0.46 and $0.04 \%$, respectively. The same picture was observed in the soil profiles of the eastern and southern slopes (Table 1).

Table 1. Bulk density, content and reserves of organic carbon and total nitrogen in the profile of brown soils

\begin{tabular}{|c|c|c|c|c|c|c|c|}
\hline Horizon & $\begin{array}{l}\text { Soil layer } \\
\text { (cm) }\end{array}$ & $\begin{array}{l}\text { Bulk density } \\
\left(\mathrm{g} / \mathrm{cm}^{\mathbf{3}}\right)\end{array}$ & SOC (\%) & $\begin{array}{c}\text { SOC } \\
\text { reserves } \\
\text { (t/ha) }\end{array}$ & TN (\%) & $\begin{array}{c}\text { TN } \\
\text { reserves } \\
(t / h a)\end{array}$ & $\mathbf{C} / \mathbf{N}$ \\
\hline & \multicolumn{7}{|c|}{ North slope } \\
\hline$A_{h}$ & $0-6$ & 1.12 & 4.52 & 30.40 & 0.46 & 3.07 & 9.9 \\
\hline $\mathrm{A}_{1}$ & $7-24$ & 1.28 & 1.72 & 43.95 & 0.21 & 5.27 & 8.3 \\
\hline $\mathrm{AB}$ & $25-33$ & 1.33 & 0.78 & 9.37 & 0.09 & 1.08 & 8.7 \\
\hline $\mathrm{B}_{1}$ & $34-60$ & 1.3 & 0.65 & 20.27 & 0.09 & 2.68 & 7.6 \\
\hline $\mathrm{B}_{2}$ & $61-84$ & 1.32 & 0.58 & 17.61 & 0.08 & 2.43 & 7.3 \\
\hline $\mathrm{BC}$ & $85-102$ & 1.31 & 0.50 & 11.76 & 0.07 & 1.65 & 7.1 \\
\hline \multirow[t]{4}{*}{$\mathrm{C}$} & $103-125$ & 1.3 & 0.30 & 7.69 & 0.04 & 1.04 & 7.4 \\
\hline & Total & & & 141.05 & & 17.22 & \\
\hline & $0-100$ & & & 133.36 & & 16.18 & \\
\hline & \multicolumn{7}{|c|}{ East slope } \\
\hline$A_{h}$ & $0-5$ & 1.13 & 3.2 & 18.02 & 0.33 & 1.85 & 9.7 \\
\hline$A_{1}$ & $6-17$ & 1.27 & 2.2 & 27.70 & 0.25 & 3.20 & 8.7 \\
\hline $\mathrm{AB}$ & $18-38$ & 1.33 & 0.8 & 20.27 & 0.09 & 2.29 & 8.9 \\
\hline $\mathrm{B}$ & $39-63$ & 1.32 & 0.8 & 27.07 & 0.11 & 3.71 & 7.3 \\
\hline $\mathrm{BC}$ & $64-86$ & 1.31 & 0.6 & 18.60 & 0.08 & 2.64 & 7.0 \\
\hline \multirow[t]{4}{*}{$\mathrm{C}$} & $87-124$ & 1.3 & 0.5 & 14.70 & 0.06 & 2.05 & 7.2 \\
\hline & Total & & & 126.36 & & 15.74 & \\
\hline & $0-100$ & & & 116.83 & & 14.41 & \\
\hline & \multicolumn{7}{|c|}{ South slope } \\
\hline$A_{h}$ & $0-5$ & 1.14 & 2.47 & 14.084 & 0.25 & 1.42 & 9.9 \\
\hline $\mathrm{A}_{1}$ & $6-18$ & 1.28 & 1.24 & 22.138 & 0.17 & 2.96 & 7.5 \\
\hline $\mathrm{AB}$ & $19-47$ & 1.33 & 0.75 & 26.073 & 0.10 & 3.56 & 7.3 \\
\hline $\mathrm{B}_{1}$ & $48-68$ & 1.33 & 0.56 & 15.713 & 0.07 & 2.07 & 7.6 \\
\hline $\mathrm{BC}$ & $69-85$ & 1.33 & 0.31 & 14.163 & 0.04 & 1.85 & 7.6 \\
\hline \multirow[t]{3}{*}{$\mathrm{C}$} & $86-110$ & 1.32 & 0.28 & 12.495 & 0.04 & 1.62 & 7.7 \\
\hline & Total & & & 104.67 & & 13.47 & \\
\hline & $0-100$ & & & 99.46 & & 12.80 & \\
\hline
\end{tabular}

\section{Conclusions}

Clay content, $\mathrm{CO}_{2}$ carbonates and $\mathrm{pH}$ are important determinants of brown soils in the Chirchik river basin, Tashkent region. The stocks of organic carbon and total nitrogen in soils varied depending on the topographic aspect and the depth of the soil horizons. The main SOC and TN stocks are stored in the upper soil layers in the Ah and A1 horizons, which indicates the importance of these layers in stabilizing the SOC and TN stocks. The microclimatic conditions of the topographic aspects of the slopes have a significant impact on the content and reserves of SOC and TN of brown soils. The content and reserves of SOC and TN soils vary depending on the exposure of the slope and decrease from the soils of the northern slopes to the soils of the eastern and especially the southern slopes. This provision emphasizes the need for a separate consideration of atmospheric carbon emissions from soils developed on different topographic aspects of slopes.

\section{References}

[1] N.H. Batjes, J.A. Dijkshoorn, Carbon and nitrogen stocks in the soils of the Amazon Region, Geoderma 89 273-286 (1999)

[2] N.H. Batjes, Total carbon and nitrogen in the soils of the world, European Journal of Soil Science 47, 151-163 (1996)

[3] R.P. Nicholas, A.L. Kathleen, M.S. Seyfried, S.E.Godsey, S.B. Parsons, Topographic controls of soil organic carbon on soil-mantled landscapes, Scientific Reports 9, 63901-63915 (2019)

[4] R. Xiao, X. Man, B. Duan, Carbon and Nitrogen Stocks in three types of Larix gmelinii Forests in Daxing'an 
Mountains, Northeast China, Forests 11(3), 305 (2020)

[5] Z. Meng, Q. Feng, Z. Mengxu, W. Liu, Q. Yanyan, R. Deo, Ch. Zhang, Effects of topography on soil organic carbon stocks in grasslands of a semiarid alpine region, northwestern China, Journal of Soils and Sediments 19(1-2), 1640-1650 (2019)

[6] M. Egli, G. Sartori, A. Mirabella, F. Favilli, D. Giaccai, E. Delbos, Effect of north and south exposure on organic matter in high Alpine soils, Geoderma 149(1), 124-136 (2008)

[7] Sh. Wang, X. Wang, Zh. Ouyang, Effects of land use, climate, topography and soil properties on regional soil organic carbon and total nitrogen in the Upstream Watershed of Miyun Reservoir, North China, Journal of Environmental Sciences 24(3), 387-395 (2012)

[8] E. Sakin, E.D. Sakin, Soil organic carbon stocks of east anatolia region in Turkey, South Western Journal of Horticulture Biology and Environment 2, 129 -137 (2011)

[9] G. Aydin, M.A. Çullu, S. Ersahin, E. Akça, E. Erdogan, L. Atatanir, A. Yorulmaz, A. Cilek, M. Ersoy, S.R. Miavaghi, S. Kapur, R. Lal, Mapping soil carbon: stocks in Turkey. In R. Lal (Ed) Encyclopedia of Soil Science 3rd Edition, Taylor and Francis, pp. 1412-1415 (2016)

[10] E. Sakin, Relationships between of carbon, nitrogen stocks and texture of the Harran plain soils in Southeastern Turkey, Bulgarian Journal of Agricultural Science 18(4), 626-634 (2012)

[11] F.Yimer, S. Ledin, A. Abdelkadir, Soil organic carbon and total nitrogen stocks as affected by topographic aspect and vegetation in the Bale Mountains, Ethiopia, Geoderma 135, 335-344 (2006)

[12] G. Abebe, A. Tsunekawa, N. Haregeweyn, T. Takeshi, M. Wondie, E. Adgo, T. Masunaga, M. Tsubo, K. Ebabu, M.L. Berihun, A. Tassew, Effects of Land Use and Topographic Position on Soil Organic Carbon and Total Nitrogen Stocks in Different Agro-Ecosystems of the Upper Blue Nile Basin, Sustainability 12(6), 14 (2020)

[13] M.A. Eunice, V. Wilner, M.M. Aldênia, R, Gilberto, A.G.R. da Silva, Land-Use Effect on Soil Carbon and Nitrogen Stock in a Seasonally Dry Tropical Forest, Agronomy 10(2), 1582020

[14] X. Nie, H. Zhang, Y. Su, Soil carbon and nitrogen fraction dynamics afected by tillage erosion, Scientific Reports 9,16601 (2019)

[15] J. Six, R.T. Conant, E.A. Paul, K. Paustian, Stabilization mechanisms of soil organic matter: Implications for C-saturation of soils, Plant and Soil 241(2), 55-176 (2002)

[16] R.K. Kuziev, V.E. Sektimenko, Soils of Uzbekistan, Tashkent Extremum Press, Tashkent, pp. 43-101 (2009)

[17] I.P. Gerasimov, Moscow About soil types of mountainous countries in vertical soil zoning, J. Soil Science 11, 530-536 (1948)

[18] I.P. Gerasimov, V.V. Dokuchaeva, Moscow Brown soils of dry forests and shrubs of meadow-steppes, $T r$. Soil. in-t them. 30, 230-235. 1949

[19] M.A. Glazovskaya,. The nature and economic conditions of the mountain zone of Bostondyk, AN Kaz R Soils of Bostandyk region, Almaty, pp. 16-35 (1956)

[20] Kh.M. Makhsudov, L.A. Gafurova, I.T. Turapov, A.A. Khanazarov, Mountain and foothill soils of Uzbekistan, their genetic characteristics and protection, III Congress of Soil Scientists and Agrochemists, Tashkent, pp. 44$55(2002)$

[21] J.C. Dixon, Chemical Weathering in Cold Climates, Editor(s): John F. Shroder, Treatise on Geomorphology, Academic Press, pp. 245-257 (2013) 